\title{
Mechanisms for the modernization of regions having agricultural specialization in the imperatives of the digital economy
}

\author{
Tatiyana Kuchnarenko ${ }^{1}$ and Liubov Pudeiyan ${ }^{1, *}$ \\ ${ }^{1}$ Don State Technical University, 1, sq. Gagarina, 344003, Rostov-on-Don, Russia
}

\begin{abstract}
The purpose of this article is to study from the perspective of a balanced modernization development of the region the mechanisms of actively involving the agribusiness sector in this process, which in a number of Russian regions of relevant specialization is considered as the main driver of their strategic socio-economic development. The methodological base of the study is formed on the basis of the convergence of systemic, synergetic and evolutionary approaches, as well as the basic principles of theories of regional economics and regional governance, the economic landscape, spatial distribution and use of resources and productive forces. The article analyzes the state and trends of the modernization development of agro-industrial complexes in the regions of southern Russia from the perspective of solving the problem of balanced socio-economic development of their territories in modern imperatives of informatization and digitalization. The authors demonstrate the possibilities of intellectualizing the potential management processes of regional and interregional agricultural holding structures. It is shown that the use of adaptive, taking into account the agricultural specialization of the regions, tools for supporting management decision-making in the field of regional agribusiness will contribute to its involvement in the regionwide dynamics of modernization.
\end{abstract}

\section{Introduction}

The process of formation of regional economies belonging to innovation and information-digital type is especially rapidly developing in the economic space of Russia in recent years due to intensive technological progress. This dynamics, both for stably developing and depressed regions, involves the establishment of priorities for measures in the public administration system for solving basic economic problems. This is based primarily on the industries and areas of activity that determine the region's profile drivers of the region's modernization transformations based on the active introduction of innovations. Among these tasks there are issues of social welfare of the population, economic security, multi-aspect use of the competitive advantages of the region due to the development of innovation sector and the information and digital sphere that "covers" all the others.

*Corresponding author: pudeyan.liuba@yandex.ru 
But despite the obvious interconnection and interdependence of the trends of regional modernization based on innovation and informatization (digitalization), in real practice, the direction of their meridians is not characterized by "cenological nesting": often these processes are not synchronized and not harmonized across the regions of the country, as well as in different territories within the boundaries of individual regions. The reason for this situation is the asymmetry of accumulated potential and regional development indicators both in interregional and intraregional aspects. According to some authors, "a number of problems in the field of resource security management in the regions are associated with a special consideration of the size of the country and a high degree of regional differences both in the availability of resources and in the level of their economic development against the background of an increase in the scale of demographic, environmental and social problems in some of them" [1]. This actualizes the solution of national task of achieving innovative digital resonance in the regions based on joint efforts of the state and business.

\section{Materials and methods}

According to a number of scientists, "following the innovation paradigm of development by most national economies, initiated by solving problems of increasing their competitiveness in the world market in the face of increasing globalization processes, as well as under the influence of a number of geopolitical challenges, involves improving public policy in relation to basic sectors of the economy that determine the macroeconomic dynamics of the country"[2], and within the boundaries of individual regions - their profile and economic status in the state.

At the same time, in the contemporary theoretical field there are several views on the strategy for the modernizing transformation of regional economies and their introduction on the path of innovative digital development. One approach is based on the paradigm that only the systematic development of the legislative base with the subsequent development of infrastructure elements of innovation and digital space of the region will allow it to go on the path of high-tech development without jerks and economic crises. An alternative view is based on the position of implementing drip innovative digital breakthroughs, which arose mainly under the influence of legislative measures included in regional innovation and information policy, in particular, through the introduction of legislative initiatives obliging business entities to take the innovative path and use information digital technologies, or create specialized R\&D funds for the right to obtain permission for a certain type of activity. This approach is consistent with the fact that in order to maintain a stable position in the market of high value-added products, the state needs to constantly improve it, that is, impart new consumer qualities. And this requires a continuous innovation process and a significant update of fixed assets, both in industrial and agricultural sectors of the regions having the corresponding specialization.

This is due to the fact that the development of agro-industrial complex for any country is one of strategically important factors that have a great influence both on the competitiveness of the state on the world market and on its sovereignty. In the system of national priorities, including those noted by the President of Russia V.V. Putin, in his Address to the Federal Assembly regarding the improvement of the welfare of Russian citizens, it is outlined that in order to maintain positive macroeconomic dynamics, "we need to launch a new investment cycle, seriously increase investments in creating and updating jobs, infrastructure, in the development of industry, agriculture, and the service sector and accelerate the digital transformation of these sectors of the economy" [3].

To improve the efficiency of processing and manufacturing sectors of regions in the agricultural sector at the present stage, along with other important tools and levers, it is 
necessary to consider the introduction of modern information and digital technologies. World experience shows that in recent decades a steady trend of large-scale and intensive informatization and automation has been formed in the field of agricultural production. Thus, the EU countries form a common agricultural policy, which combines the elements of regulatory, market, pricing, foreign trade and structural policies based on an informationdigital platform, applying in the agro-industrial sector the full range of achievements in this field. Since sectoral and territorial factors are integrated in the agrarian economy of these countries, the innovation and informatization of this sphere is a key condition for regional modernization. In the framework of the policy of modernization of agricultural production and the agro-industrial complex implemented in the EU countries, state support for the development of rural areas specializing in the production of a certain type of product is being considered. Moreover, the policy of integrating the potentials of various agricultural territories in the form of agro-industrial regional and interregional clusters, which have synergistic advantages in informatization and digitalization, is very widespread.

Thus, the existing experience of innovation and informatization of agricultural production in the EU countries indicates the implementation of a set of public policy measures taking into account factors of internal and external environment for the transition of agro-industrial complex to a model of innovative development on a modern digital information platform. Among these measures is the formation of specialized private-state structures responsible for determining the vector and implementation of innovative and information-digital policies in the agro-industrial sphere; implementation of active international cooperation in the field of innovation regarding the exchange of modern agricultural production technologies; creation of systems of interregional innovative agroindustrial clusters on the basis of regional innovation; creation of a cluster core of the innovation process in the sector of agro-industrial complex, which provides system integration and generation of innovative knowledge and technological solutions with the subsequent successful commercialization of innovative products.

\section{Result sand discussion}

In a comparative context, we can say that agribusiness in Russia has also reached a certain maturity by now, including in terms of stabilizing investment in agriculture for innovation, informatization and digitalization, as well as increased competition among agricultural producers. As actual practice shows, in the agro-industrial complex of the Russian regions "the volume and quality of the use of modern technologies, including systems for collecting, storing and processing data" is growing. Data from satellites, sensors, from operating and transactional systems are applied. This increases both the amount of data and the need for high-quality processing and reliable conclusions that you can rely on when making decisions. As a result, the demand is formed for industrial information-analytical systems and, in particular, for in-depth analytics [4]. In other words, a basic platform and tools for supporting the adoption of scientifically sound management and other decisions by the management of agricultural enterprises and agricultural enterprises of the regions are being formed.

At the same time, despite significant successes in this area, even if there are competitive advantages in relation to a number of other countries with priority agricultural economies, Russia does not fully take into account a number of factors that impede the more efficient use of natural resources, geographical, human resources and other types of potential of agricultural regions. Among these factors there are climatic risks, insufficiently favorable investment climate, relatively slow investment payback periods, underdeveloped innovation and information infrastructure in a number of regions of the country. In addition, as noted earlier, "the high diversity of territorial factors and conditions (directly correlating with the 
historically existing high differentiation of regions in terms of resource and other types of potential and levels of socio-economic development)" [5] determines peculiar modernization policy based on innovation. It also determines the multiplicity of options for the formation of regional systems for managing these processes, including in terms of their subject-object certainty in the field of agribusiness.

Given the above, we can consider the target integration of agro-industrial sector of the region into the region-wide modernization processes, based on wide scaling of innovations as a public-private investment project of a special kind. This is due to the fact that, according to the study results, the development of agricultural sectors in various countries is more dependent on private investors.

This circumstance is also applicable to the Russian practice of modernizing the economies of regions having agro-industrial specialization and determines the following features of innovative projects in the agricultural sector:

1. a high degree of uncertainty in the results, determined by both the long-term and the scale of projects related to the implementation of technological and product innovations;

2. the presence of immanent risks inherent in innovative projects and a relatively long payback period determined by these risks, as well as by a high degree of multidirectionality of participants' interests;

3. the need to attract large volumes of investment from various sources, especially when it is associated with the transfer of a significant part of production processes in agricultural sector to the platform of new automated, electrified and information-digital intensive technologies;

4. objectively existing complexity of reliable and correct substantiation of the effectiveness and selection of one of the alternative innovative projects, which is explained by the poor knowledge of development patterns of innovative processes in agricultural sectors and the lack of high-quality methodological support for the assessment, taking into account the uncertainty and risk noted above.

Today, the success of investors also depends on timely access to objective and complete information about the object of innovation, a thorough study of the market situation and the behavior of competitors. The need to solve problems related to the profitability of investment activity in the field of innovation at agricultural enterprises, increasing competitiveness and technical and economic requirements for the quality of products, along with solving economic, social, environmental problems in the agricultural sector, determine the quantitative and qualitative assessment of the feasibility of investments in innovative projects.

It seems at the same time that state support for modernization processes based on the introduction of various innovations should be considered to a greater extent as creating an enabling environment for agricultural sectors. The introduction of innovative technologies allows not only to improve the quality of products, but also to reduce their cost. However, this requires a regulatory function of the state in the domestic market to ensure the final price of products that allows achieving a balance of interests of its producers and consumers, especially in the context of existing sectoral sanctions. In other words, a set of state measures is needed aimed at such a change in the situation on the domestic agricultural market, which, on the one hand, will help solve the problem of food security, and, on the other hand, ensure modernization processes in these strategically important sectors.

In methodological and applied aspects, it is important to take into account the fact that, depending on specific regional factors and conditions (regional determinants), certain elements of the regional economy's potential (industries, spheres, types and directions of activity) will play a different role and have different meanings for regional development. 
This can be, in particular, system-forming functions (if these types of activities occupy a predominant share in the structure of regional economy, and the quality of all other industries and the social sphere depends on the effectiveness of their functioning). These may be modernization functions (when a particular type or field of activity is the leader on a regional scale in the success of modernizing transformations). It can also be innovative functions, when a particular area of activity acts as a driver of regional innovation systems. And finally, these may be functions of the active implementation of the policy of informatization and digitalization.

One should note the possibility of convergence of all these functions within the framework of individual areas of activity or sectors of the regional economy. At the same time, as practice shows, in almost every region or macro-region it is possible to distinguish sectors (industries) that occupy prominent positions in the regional economic system.

For example, the economy of the Southern Federal District is a combination of such industries as: engineering, rock mining, agriculture and diversified leisure complexes. Each of these areas can be characterized by one or more of the above role functions in a given macro-region, while strengthening its priority value for a particular region, including on the basis of a common technological, innovative, information, digital and other platform.

If, in particular, in the field of regional agribusiness, we are talking about a technological integration platform, it should be noted that this approach is characterized, among other qualities, also by saving on diversity. It takes place when the reduction in costs for manufacturers is achieved by combining several different types of production "under one roof". Its source may be, as in the case of corporations, the use of internal (transfer) prices of products and resources in mutual settlements, the use by the interacting companies of the same resource or the same production technology of various types of products, etc.

It seems that such savings are an incentive for related diversification rather than vertical integration. In addition, it should be borne in mind that along with the increase in the scale of technological interaction of agricultural enterprises, the management process is becoming more complicated, and consequently, management costs are increasing. The creation of such an association (for example, a regional cluster) from scratch to carry out activities in the new sphere is also associated with significant investments. The combination of production factors into a single organizational structure, in other words, the establishment of an integrated structure, represents the maximum degree of continuity of economic relations of its participants - representatives of different industries. Such a unified structure will continue to function even when, due to the emergence of new opportunities, integration has ceased to be economically attractive for all or its individual members.

However, after external changes reach a critical level, internal reorganization (transformation, diversification, modernization) of the integrated structure begins. So, diversification is carried out to increase the sustainability of the business and to increase the value of the corporation (cluster). Horizontal diversification in the field of agribusiness is understood as expanding the assortment of new products that require new technology that is different from the one used, but that can cause interest among traditional buyers. At the same time, it seems possible that the association diversifies into both related and unrelated industries. To make this kind of organizational decisions, the association's management assesses the real possibilities for the company to achieve its planned profit targets and ensure the return on investment, and also determines the degree of necessity and the size of investments in innovation. Diversification into unrelated industries (conglomerate merger) also has certain advantages. In this case, the company can distribute production, financial and other risks in many areas, which can contribute to the distribution of risks associated with innovative projects between participants.

Thus, cluster initiatives in the agricultural sector make it possible to provide closed innovation chains, which also involve educational and scientific organizations, and form the 
supporting links of the economic framework for the innovative development of the region as a whole [6], that is, a kind of "regional innovation belt" in the agricultural sector.

In order to sell the products of the association in new segments, it is necessary to significantly increase the knowledge of the company's employees, since human capital is the main factor in the goal-oriented organization and the effective use of the entire integrated potential of participants of the agricultural holding association. A vivid example is the Rostov region, which tests the confident integration of innovative processes in the regional agribusiness and the high efficiency of agricultural enterprises of the region determined by this.

To a large extent, this is determined by the use by the management of the association and its structural divisions of modern management methods and organization of activities of the agricultural holding based on the use of modern tools to support the adoption of managerial decisions regarding its potential, including economic, mathematical, information and technological and digital. The latter makes it possible to consider such associations as virtual corporations of a special type. "This form of organizational and economic consolidation is based on new ways of integrating industrial enterprises and scientific organizations in the implementation of joint projects related to the introduction of computer technology. In this case, the main effort of the virtual structure is aimed at preserving the differences between partners (and thereby the diversity of their resources) while recognizing collective values and striving to achieve common goals through active inclusion in decision-making processes by means of direct communication channels between relatively equal partners" [7]. This is another important incentive for such joint activities of the participants.

One of the options for information-analytical platform for making managerial decisions regarding the potential of agricultural holding association can be considered in a following way, proposed by the authors of this article.

We will consider the potential management system of the agricultural holding cluster as a structural and functional subsystem of regional management as a whole, as well as a relatively separate system. That is, it can be considered, on the one hand, as part of the region's management system, which is an external environment for association and, on the other hand, as an element of the corporate governance system, which acts as the internal environment of the cluster.

Let us consider the basic conceptual models of potential management of an agricultural holding cluster, which determine the role and place of the potential management system of an agricultural holding cluster in the region in different ways.

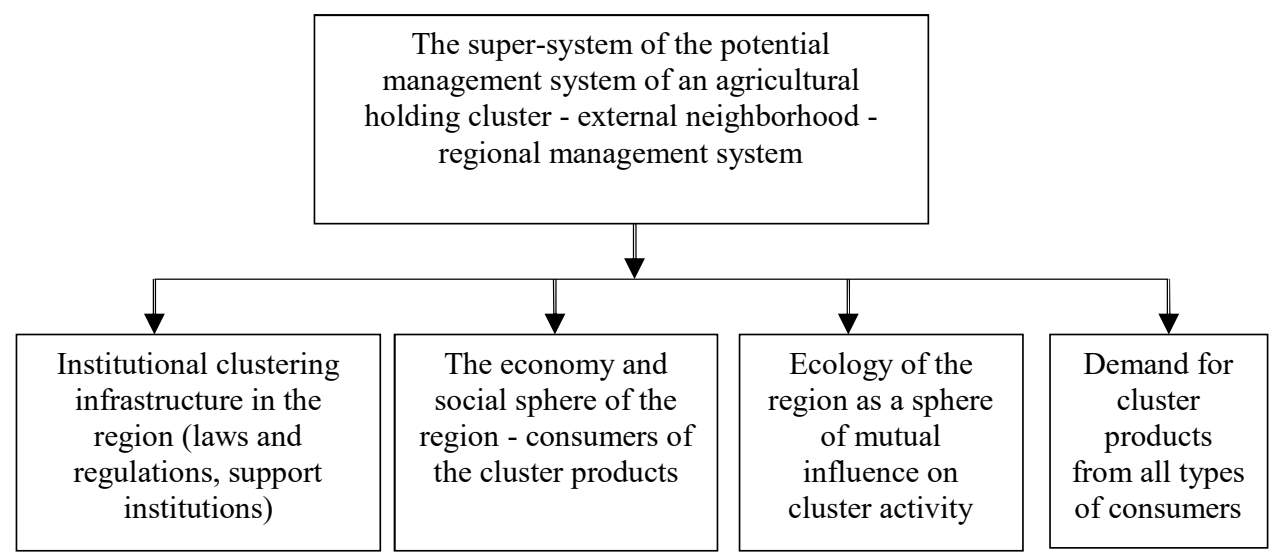

Fig. 1. The structure of the super-system of the potential management system of an agricultural holding cluster. 
As a result, we obtain the structure of the super-system of potential management system of an agricultural holding corporation, shown in Figure 1.

At the same time, the so-called "friendly environment" includes cluster partners for joint activities (including the state), as well as all entities that are potential consumers of products manufactured by the agro-industrial cluster, that can interact with the cluster subsystem that sells these products. Such interactions of the agricultural holding cluster with an external friendly environment are carried out on the principles of mutual trust and partnership, including in all areas: socio-economic, institutional, infrastructural, environmental, information and other.

Goals ("outputs"), forms of activity of the agricultural holding cluster potential management system, methods for achieving the goals of management system, means of implementing the goals of this management system and "inputs" of the management system are distinguished by such indicator as the "activity structure" (Fig. 2).

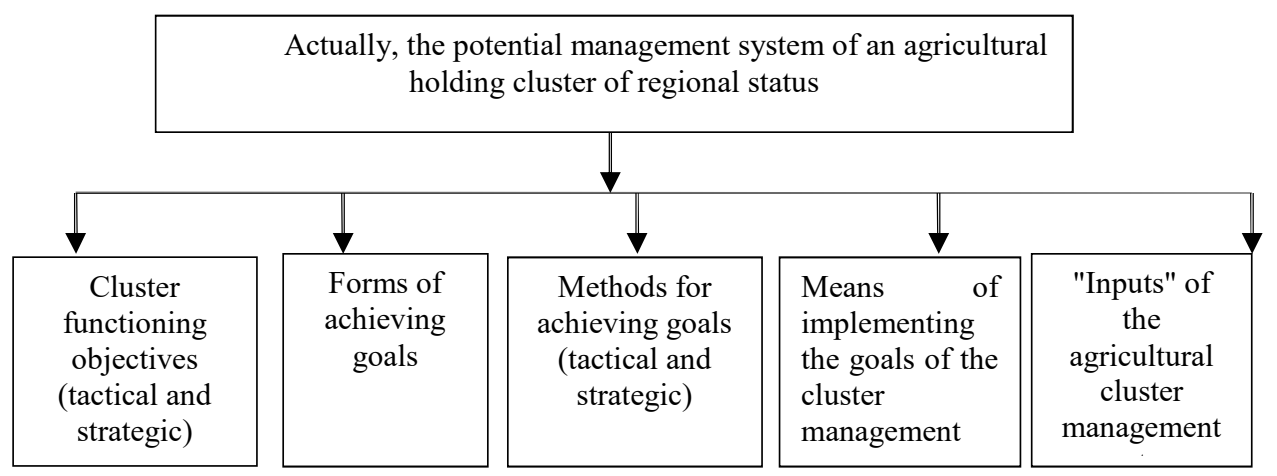

Fig. 2. Elements of an agricultural holding cluster potential management system.

Within the framework of the adopted approach to the formation of an agro-industrial cluster management system in the region as an integrator and implementer of the idea of a balanced modernization development of the agro-industrial sector of the region, Figure 3 shows an approximate structural model for consistent implementation of the main and secondary goals of the cluster.

As can be seen from the contents of the above figures 1-3, the potential management of the agricultural holding cluster has a multidimensional nature: firstly, it is the most important factor in the socio-economic development of any region, especially of agricultural specialization; secondly, it is the most important environmental instrument of the regional management system; thirdly, managing the potential of an agricultural holding cluster on a scientific, methodological and modern instrumental digital information platform can be considered as an effective and long-term way to achieve profit. Moreover, it can be considered both in the intra-cluster (within the framework of this model, individual elements of the potential management system of the agricultural holding cluster are oriented towards the maximum achievement of local goals), and in the regional aspect; fourthly, the potential management of an agro-holding cluster appears in such a vision as a conscious need in modern conditions, since this model (Fig. 3) assumes that the goal of managing the potential of an agricultural holding cluster is to satisfy the need for output produced by the cluster, in the context of maximizing profits for a given business entity (the cluster itself), its participants and, in general, the regional economy system. 


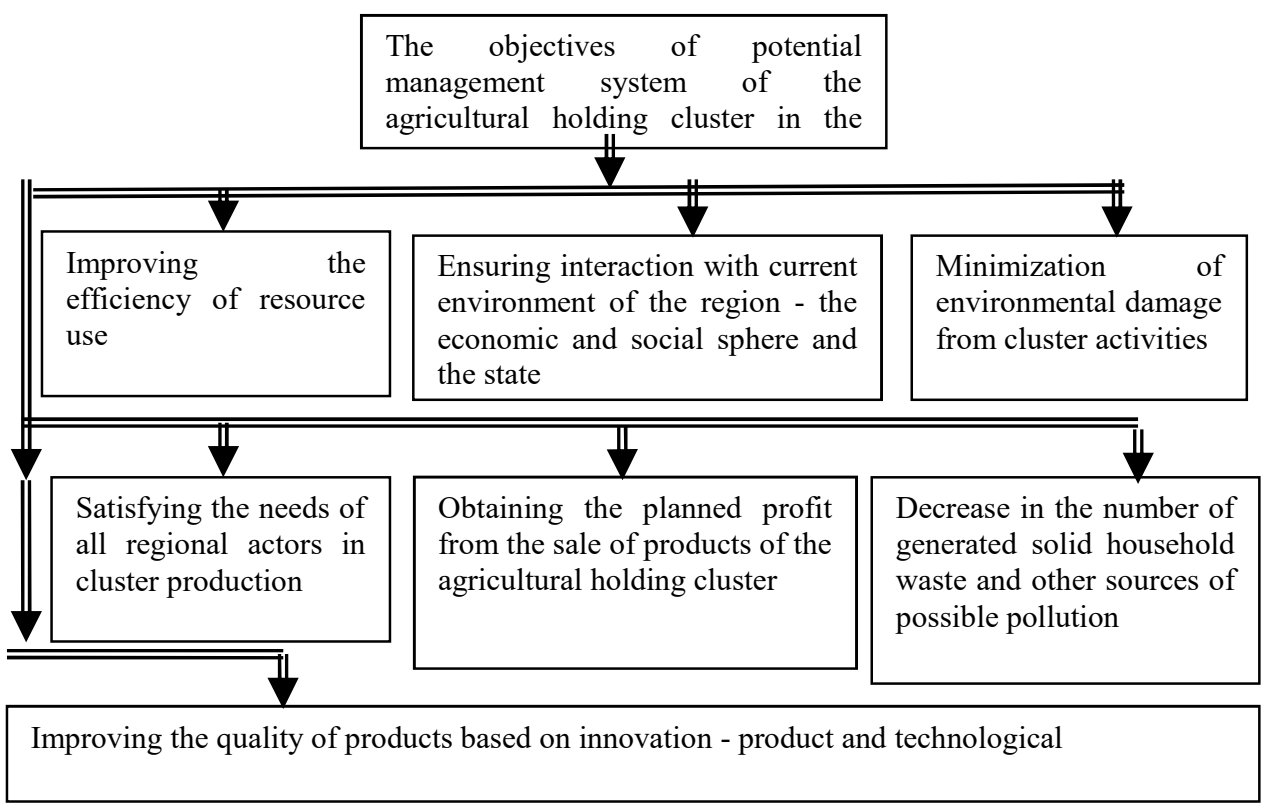

Fig. 3. Structuring the goals of potential management system of an agricultural holding cluster.

The main means of implementing the corporate and private goals of participants in the agro-industrial association are shown in Figure 4. 


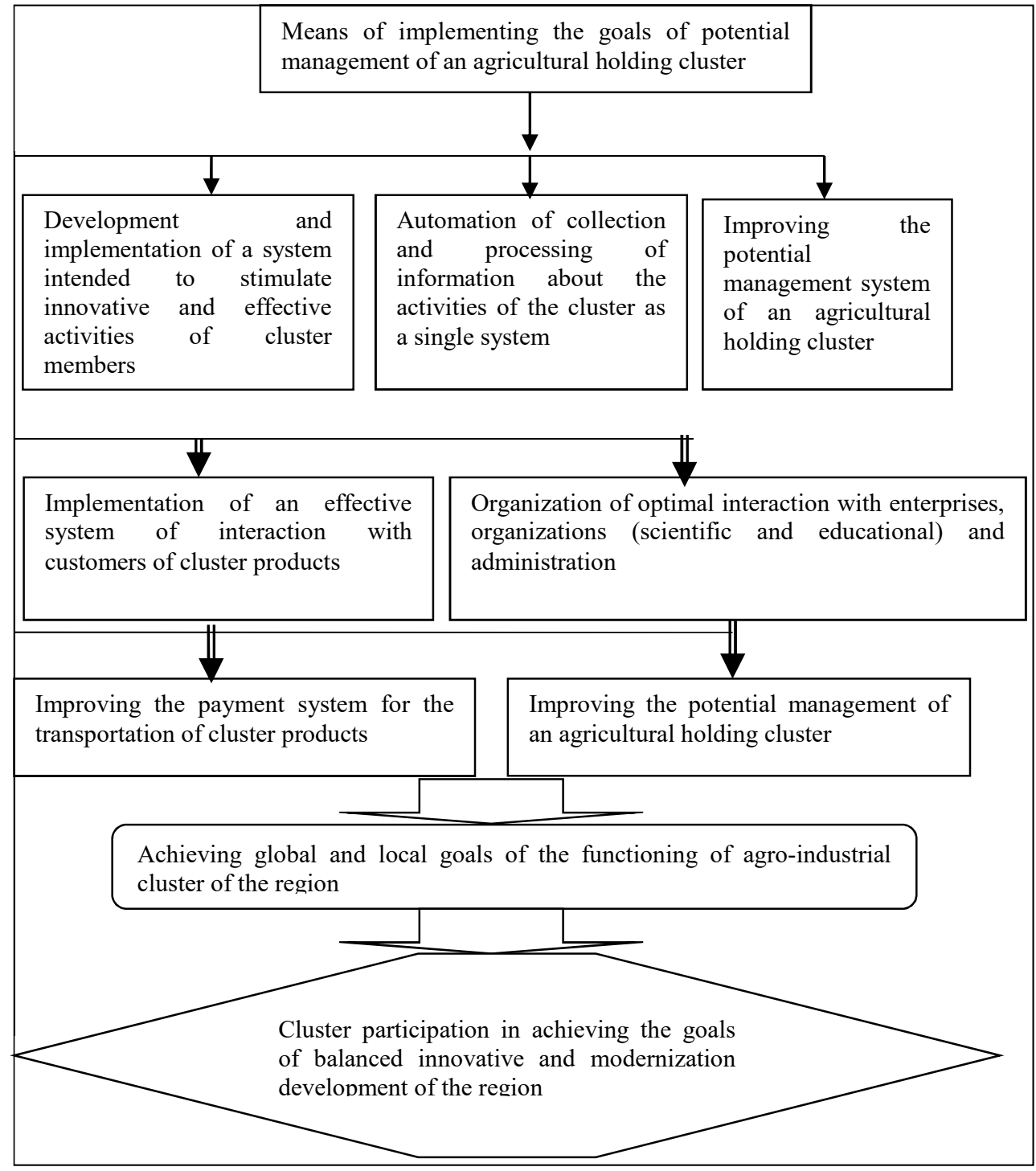

Fig. 4. Means of implementing the goals of potential management of an agricultural holding cluster.

\section{Conclusion}

According to the authors of this article, "the creation of a virtual enterprise (including in the agricultural sector of the region) means the integration of unique experience, production capabilities and advanced technologies of partner enterprises, uniting around a project that cannot be completed by each partner individually. The formation of a virtual enterprise from heterogeneous production systems provides mutual compensation of their shortcomings and enhances their advantages, which contributes to the generation of a synergistic effect" within the agricultural holding structure itself, as well as multiplicative effect in various sectors of the regional economy and the region's population. 


\section{References}

1. D. Acemoglu, U. Akcigit, N. Bloom, W. Kerr Innovation, Relocation and Growth (2013) http://economics.mit.edu/files/8790

2. R. Bukh, R. Heeks, Defining, Conceptualising and Measuring the Digital Economy. Global Development Institute working papers 68 (2017) https://diodeweb.files.wordpress.com/

3. E. Bornhofen, T. Ramires, T. Bergonci, L. Nakamura, A. Righto, Agricultural Systems 173, 281-288 (2019)

4. M.V. Kazakovtseva, F.Z. Gumarova, E.I. Tsaregorodtsev, Mediterranean Journal of Social Sciences 6(3), 213-220 (2015)

5. C. Perez, Techno-Economic Paradigms (Anthem Press, The Other Canon Foundation, London, 2011)

6. M.V. Gestrin, J. Staudt, The digital economy, multinational enterprises and international investment policy (2018) http://www.oecd.org/investment/investmentpolicy/The-digital-economy-multinational-enterprises-and-international-investmentpolicy.pdf

7. A.V. Shokhnekh, N.N. Skiter, A.F. Rogachev, T.V. Pleschenko, E.V. Melikhova, Journal of Advanced Research in Law and Economics 7(7), 1854-1857 (2016)

8. D. Tapscott, The Digital Economy: Promise and Peril In The Age of Networked Intelligence (McGraw-Hill, 2014)

9. L.G. Matveeva, A.Y. Nikitaeva, and O.A. Chernova, Terra Economicus 16(1), 134145 (2018)

10. N.A. Kosolapova, L.G. Matveeva, A.Y. Nikitaeva, L. Molapisi, Journal of Hydrology 553, 438-446 (2017)

11. C. Juma, The New Harvest. Agricultural Innovations in Africa (Oxford University Press, Oxford, 2011)

12. K. Fuglie, S. Wang, Amber Waves 10, 1-6 (2012)

13. K. Fuglie, Global Food Security 10, 29-38 (2016)

14. V. Mau, The Russian economy in 2017. Trends of Perspective (Publishing house of the Gaidar Institute, Moscow, 2018)

15. A. Mazur, K. Mazur, East European Scientific Journal 53(5), 31-36 (2020)

16. V.G. Zakshevsky, O.G. Charykova, I.N. Merenkova, Strategic Priorities For Developing The Agro-Industrial Complex And Rural Areas Of The Region, IOP Conference Series: Earth and Environmental Science (2019) 